\title{
Community Participation in Local Government Planning Processes: A Paramount Step Towards a Successful Service Delivery
}

\author{
Thanyani S Madzivhandila
}

Department of Development Planning \& Management, University of Limpopo, South Africa

Private Bag X1106, Sovenga, 0727 thanyani.madzivhandila@ul.ac.za

Caswell M Maloka

Department of Development Planning \& Management, University of Limpopo, South Africa

Private Bag X1106, Sovenga, 0727 caswell.maloka@ul.ac.za

\section{Doi:10.5901/mjss.2014.v5n16p652}

\section{Abstract}

In recent years, planning for service delivery mandate has been strategically shifted from a centralised (national) to a more localised (municipal) sphere of government. That is, planning is no longer seen as a top-down but rather regarded as an inclusive process where communities are viewed as key stakeholders. In this sense, community participation is seen as having a major implication on democratising service delivery beyond just representative government but locating users and communities as central role players in the process. Community participation in this context offers a greater control of the underprivileged over their own situation and ensures their full involvement in determining their own developmental needs. Therefore, municipalities must play a significant role in promoting democracy and ensuring that communities participate in decisions that affect them directly. The article argues that despite its complex structures, obstacles and severe managerial challenges, community participation remain paramount to the success of planning for service delivery. This article discusses the concept of community participation as a prerequisite for successful governance and service delivery in the local sphere of government. It also examines the challenges and obstacles facing community participation during the planning and implementation processes of integrated development planning (IDP) as a tool for delivery of services in the local sphere of government. Practical possible solutions on the facilitation of a successful service delivery process are considered. The article concludes that an improved means of community participation and involvement in IDP processes is essential for service delivery.

\section{Introduction}

The South Africa democratic government adopted developmental approach to local government in order to eradicate the legacy of the past apartheid regime. Community participation in the local planning processes has become paramount to changing role played by local government in South Africa since 1994. The idea of community participation was supported by the promulgation of various legislative frameworks which encouraged the involvement of community members in local governance and policy making. For example, the White Paper on Local Government (1998) defines developmental local government as government committed to working with citizens and groups within the communities to find sustainable ways of meeting social, economic, political and material need and improving their quality of life. This approach to development aims to enhance skills and capacity of community members by promoting participation in their own development processes. Thus, integrated development plan (IDP) provides opportunity to both the municipality and community to work together in local governance. The Municipal Systems Act (Act 32 of 2000) requires for the adoption of IDP as a strategic planning tool that supersede all other plans which identify the challenges and development objectives in a municipality. Therefore, community participation serves as an indispensable mechanism that could allow for a successful integrated development planning at the local sphere of government. The article provides an argument that community participation remain a crucial step towards the success of planning for service delivery despite its diverse challenges. The debate of this article begins with the solid conceptualisation of community participation in the context of service delivery within municipalities. Followed by a discussion about community participation as a prerequisite for successful governance and planning for service delivery. The article then discusses the importance of community participation into the integrated development planning (IDP) process. Lastly, the article presents a range of significant obstacles and challenges facing community participation in planning for service delivery, as well as concluding remarks. 


\section{The Concept of Community Participation}

The concept of community participation can have variety of meaning relating to a particular context. The conception of community participation in South Africa is largely linked to the planning and management of development activities at the local sphere of government (Ababio, 2004; Moseti, 2010; Madzivhandila \& Asha, 2012). This is because local municipalities are regarded as the sphere of government that is closer to the people and the pillar of democracy (Republic of South Africa, 1998). Municipalities can therefore play a developmental role by among other things; ensuring that people are at the centre of local government initiatives. For this reason, municipalities in South Africa are required through legislative frameworks to encourage the involvement and participation of the ordinary members of the society in decisions that affect their well-being. Community participation is defined as an active process of organising communities to take part in the socio-economic and political activities of their locality, making them effective participants and beneficiaries of collective decisions that have been taken and executed (Nsingo \& Kuye, 2005). Ababio (2004) also defined it as the process by which local stakeholders such as community members, government institutions, local businesses, community based organisations (CBOs) and non-governmental organisations (NGOs) work collectively in decision making that influence development outcomes in a municipal jurisdiction. Therefore, community participation is a mechanism through which communities and local stakeholder can be involved in matters pertaining to local governance.

Community participation provides opportunities for the community to express their views in development projects. Thus, the planning and implementation of these projects should be accepted only after considerable discussion and consultation with communities (Mbambo \& Tshishonga, 2008). This process allows marginalised individuals to have voices in the future development initiatives. Hence, it enables for full involvement of ordinary members of the community in decision making, planning, designing, organising and executing development initiative that affect them. The involvement of people should create consensus between different stakeholders and a sense of ownership of development initiatives and allow them to share equitably the benefits resulting from such development (Nsingo \& Kuye, 2005). Basically, this allows people to direct and implement development projects with the view of improving their standards of living in terms of jobs, income, empowerment and self-reliance. Nzimakwe \& Reddy (2008) argues that community participation form part of domestic engagement and citizenship which is fundamental to the principle of good local governance. It incorporates the poor and marginalized in local affairs, to take ownership of local resources and make appropriate decisions to use such resources in a sustainable manner. Therefore, participation means empowering communities by developing skills and abilities that enables them to engage and make informed decisions with regard to their developmental needs. According to Moseti (2010), participation serves as a tool for closing the gap between local government, civil society, private sector and the general community by developing a common understanding about local situation, priorities and programmes. Therefore, the aim of community participation would be to promote transparency, accountability in governance and create ownership of development decisions as well as programmes and project (Tshabalala \& Lombard, 2009). It can therefore, argued that community participation serve as a crucial component of good governance and effective service delivery.

\section{Community Participation: A Prerequisite for a Successful Service Delivery}

Community participation, that is, the direct involvement or engagement of ordinary people in the affairs of planning, governance and overall development programmes at local or grassroots level has become an integral part of democratic practice in recent years (Cornwall \& Gaventa, 2001; Pycroft, 2000; Heller, 2001; McEwan, 2003; Burde, 2004; Williams, 2006: Madzivhandila \& Asha, 2012). In South Africa for example, the Constitution of the Republic, 1996 provides that the final form of local government should be developmental. The White Paper on Local Government (1998) established the mechanism by which developmental local government could be achieved. Community participation is found to be a valid mechanism to promote such a developmental mandate in higher prominence as it hold strong appeal for multiple actors such as communities and civil societies (Burde, 2004; Williams, 2006). In the past, there has been a tendency to respond to the gap that exists between citizens and state institutions in one or two ways. Firstly, attention has been made to strengthen the process of participation in that the poor people exercise voice through new forms of inclusion, consultation or mobilisation designed to inform and to influence longer institutions and policies. Secondly, growing attention has been paid to how to strengthen the accountability and responsiveness of those institutions and policies through changes in institutional design and a focus on the enabling structures or good governance (Cornwall \& Gaventa, 2001).

Current trends of community participation are complex but manipulated to the municipality's advantage in multiple ways to varying effects, for instance, supporting community association to deliver social service when state remains weak can significantly revise the relationship of the state to its citizens. According to McEwan (2003), the act of including the 
voices and concerns of beneficiaries in the projects and other development initiatives that are meant to help them offers a counter weight to traditional top-down development approach. Hence, such interaction exposes communities to vital information which serve to generate a radical consciousness amongst them with regard to the possibilities for transformative planning and budget allocations for development purpose. Community participation in the local government decision making is also influenced by the integration and mutual interaction between all spheres of government. In reality, most of local government institution are still facing challenges associated with finance and human resources capacity, hence cooperation between three spheres of government to direct resources to local areas become a prerequisite for the success of development facilitation at the municipal level. Furthermore, Pycroft (2000) argues that, empowered local governments deepen democracy on both counts because they facilitate a better alignment of decision making centres with local preferences and local sources of knowledge and information and because it creates lot of participation that reduce the costs and unevenness of collective action. For example, in South Africa, which is characterised by a lack of strong civil society structures which can represent the interest of the majority of community members, as well as apparent lack of capacity among citizens to respond meaningfully to the complex matters, more resources should be channelled towards strengthen local government in order to facilitate meaningful participation of the ordinary people (Madzivhandila \& Asha, 2012).

The act of incorporating communities particularly previously marginalised or disadvantaged groups expands the scope and depth of citizenship and allow for sustainable decision making expanding the depth means into the process of service delivery (Heller, 2001). The more citizens are increasingly considered to have opinions that matters and experiences that count, municipalities should take it further and involve them in the kind of decisions that are currently presented as technical, rather than acknowledged as value- laden and political. This kind of active participation guard against political elected representatives becoming purely advocates of the bureaucracy. Furthermore, Cornwall \& Gaventa (2001) contends that, it is only when people are afforded power to achieve specific concrete goals such as implementing a specific plan or projects that present participation as significant process at the local level. The act of consultation without attention to transfer power and authority of decision making will lead to voices without influence. Communities should stand as makers and shapers rather than as users and choosers of intervention or service designed by others. Traditional forms of political representation should be re-examined and direct democratic mechanism should increasingly be drawn upon to enable citizens to play a more active part in decision which affect their lives (Burde, 2004; Williams, 2006). The right of participation in social-economic, cultural and political decision-making should be facilitated in the nexus between basic human rights as outlined in the constitution through adoption of the IDP process.

\section{Community Participation in the Intergrated Development Plannning Processes}

Community participation and IDP are seen as locally based planning instruments that could enable municipalities and communities to respond to poverty, unemployment and inequality (Govender \& Reddy, 2011). This development planning approaches are based on the principle of inclusive and representative consultation and participation of all residents, communities and stakeholders in local governance (Heydenrych, 2008). IDP is defined as participatory planning processes aimed at developing a strategic development plan to guide and inform all planning, budgeting, management and decision making in a municipality (Madzivhandila \& Asha, 2012). This approach to planning involves the entire municipality, stakeholders and citizens in finding the best solutions to achieve long-term development objectives. IDP is viewed as bridging together of many stakeholders as possible to delineate, define and promote their common interest (Tshabalala \& Lombard, 2009). It enables communities and local stakeholders to define their goals, needs and related priorities in a municipal area. This could be achieved through structured participation and establishing the conditions for public's involvement throughout the cycle of planning, implementation, monitoring, evaluation and review (Mubangizi, 2007). IDP is supposed to be the business plan of each municipality based on what and how it is going to benefit the communities under its jurisdiction. The communities should be informed, consulted and be allowed to participate in the planning process that concerns their needs and future. Therefore, municipalities should be responsible for the coordination the IDP and ensure adequate involvement of all stakeholders in the area. This process could lead to the empowerment of the community and enhancing their capacity to influence the IDP process in a meaningful way.

South Africa's government associates community participation in the IDP process with democracy and governance. Community participation in IDP processes is viewed as one of the ways of enabling interaction between local government and citizens. The White Paper on Local Government (1998) clearly indicates that community participation process in the IDP should be a bargaining platform between government and the community, thereby requiring communities to be actively involved in decision-making. The rationale for integration in planning is based on acknowledgement that there are many challenges facing communities and that integrated development planning would 
help municipalities to resolve these challenges (Govender and Reddy, 2011). Therefore, IDP allows for co-ordination between different stakeholders and municipalities to better understand the dynamics that exist in their development areas and enable them to meet the needs of communities and improve their quality of life by developing clear visions and strategies (Ingle, 2008). As a result, possible methods for community participation in the IDP processes prescribed by legislation include the use of IDP Representative Forums and ward committees.

The role of the IDP Representative Forum is to ensure representative participation in the IDP process. The significance of this forum is to ensure that interests of various stakeholders and communities are represented in the IDP process (Nzimakwe \& Reddy, 2008). The forum also facilitates a way in which debates, negotiations and decision-making can take place among various stakeholders and local government. This Forum allows communication between various stakeholders and local government. It serves to monitor the performance of the planning and implementation process of the IDP. The ward committees are expected to play a major role in ensuring participation of citizens in the IDP process (Ababio, 2007). The role can be achieved by organising IDP participation processes at ward level through community based planning. This kind of planning requires functional ward committees who develop plans for their own wards, and link ward priorities to the integrated development planning of the municipality. The councillors, officials, and ward committees have the responsibility to ensure that plans of a municipality reflect the needs of its citizens (Heydenrych, 2008). Therefore, without community participation developmental local government will be meaningless and the IDP of any municipality will be devoid of reality. However, they are a number of challenges associated with the implementation of community participation programmes and IDP.

\section{Obstacles and Challenges Facing Community Participation in Planning}

A participation method of governance and decision-making are deeply influenced by the contradictions, tensions, conflicts and struggles not merely the political relations of power but also the economic and ideological apparatus at local level (Pycroft, 2000; Williams, 2006; Piper \& Deacon, 2008; Madzivhandila \& Asha, 2012). In the cause of this endless rhetoric and multi platitudes, the very concept of community participation has been largely reduced to a cumbersome ritual (Williams, 2006). The situation highlights the complexity around the relationship between government and citizens and, most importantly, the failure to satisfy some of the obligations that flow from such convolution. In fact, this is a real concern because municipal IDPs lack specific relevant information, which should be provided to households, about services in a given period of time. This implies that there is a lack of transparency. Concurrently, participation alone has not resulted in visible or desirable results as it so often reduced to a mere ceremonial presence of participants in local institution. Informed discussion and rational debates on the merits and demerits of specific planning programmes are literally non-existent, even though community participation features as a key component of planning programmes at the local level. According to Piper \& Deacon (2008), the tension between individual's ambitions and collective goals on governing institutions is often mediated by party notions of accountability. Whatever their operational defects, grassroots based forums such as ward committees or sub-council often exist to gain acceptance from citizens for local forms of decentralised governance where the notion of public participation fulfil such a legislative role. In the post-apartheid South Africa community participation initiatives are largely spectator politics, where ordinary people have mostly become endorses of pre-designed planning programmes (Williams, 2006). The road towards building confidence in the willingness of government to hear rather than simply to listen, and do what they were going to do at the first place is coupled with many challenges including insufficient community participation facilitation tools.

The Constitution of the Republic of South Africa 1996 provide for the need for community participation in planning for service delivery. However, it does not identify clear measurements of its successes and failures in development planning at the grassroots level. There are no real institutional structures to coordinate, evaluate and monitor community participation in the formulation, implementation and evaluation of IDP. This exacerbates the potential for institutional conflicts in community participation. Moreover, community participation in relation to the IDP had turned into a ceremonial exercise and not a systematic engagement of communities that is structurally aligned to the development and service delivery programme (Williams, 2006; Piper \& Deacon, 2008). Furthermore, Williams (2006) adds that scheduled meetings of municipal councils are been marred by lack of the requisite facilitation or coordination infrastructure and skills to optimise community participation; lack of public transport to and from the venues of the meeting; and, lack of logistical capacity and human resource.

The election of ward committees to represent communities in IDP meeting is also flowed by many challenges. The establishment of these committees in the context of post-apartheid local government reform was an attempt to enhance public participation in the issues of local governance. However, the question is whether ward committees are offering the opportunity for local communities to engage, and hold officials and councillors accountable independent from governing 
party agenda or they are an innovation dominated by and even advancing the interest of local political party branch. In many instances, ward committees are found to be simply extensions of the local governing political party branch and reflect the pathologies associated with the dominant party syndrome. Moreover, these ward committees are allowing for little community members to voice alternatives to the dominant political leadership agenda.

The differential outcome of participatory democracy arises in part from a complexity of uneven power relations, trust and lack of belief in having a long-term impact on the status quo, often people do not trust their representatives as they are mostly co-opted by systems and are thus perceived as not being caring about their constituencies whom they are supposed to represent and account to. Citizens also are found to express disinterest because cynical public officials simply go through the motions of including them with no real commitment to change (Pycroft, 2000). In other instances, Williams (2006) argues that communities attend the supposedly participatory meetings as ill-informed or non-informed spectators, hence the attendance tend to decrease in public participation meetings. Municipal officials tend to avoid explaining the current state of service delivery to communities, the purpose and how the IDP would evolve, its benefits and the consequence if community members do not participate in the planning process. This has been linked to municipal official who are unskilled, lack the required training and knowledge base in public and development management methodology to function optimally. Concurrently, there are those communities who choose not to participate as a result of negative perceptions or experience such as language barriers, lack of funding, fear of government and its agents.

\section{Conclusion}

This article dealt with the conception of community participation. It also provided discussions about community participation as a prerequisite for a successful governance and service delivery in the local sphere of government. Furthermore, the role of community participation in the integrated development planning was discussed. It examined the challenges and obstacles facing community participation in the IDP processes and service delivery. To this end, it can be argued that communities should not cease to engage in social mobilisation, they should refocus their organisational and mobilisation energies and goals to ensure socio-economic development programmes commensurable with their enshrined constitution rights. Communities should organise themselves into civil bodies that can represent their interest at local government planning processes. By so doing, they will sustain dialogue between municipalities and their communities in all aspects of local governance. Municipalities should be guided by legislative prescripts to ensure transparency and accountability in the management of their affairs. Moreover, community members should redress challenges associated with party politicisation of development and participatory structures, lack of commitment towards prioritising community participation, lack of capacity among stakeholders, poor access to information, and failure to recognise and work closely with community-based organisations.

\section{References}

Ababio, E. P. 2004. Enhancing community participation in developmental local government for improved service delivery. Journal of Public Administration, 39(2):272-289.

Ababio, E. 2007. Marriage for development: ward committees as partners in participatory democracy. Journal of Public Administration, 42(7):614-621.

Burde, D. 2004. Weak state, strong community? Promoting community participation in post-conflict countries. Comparative Education, 6(2):73-87.

Cornwall, A. \& Gaventa, J. 2001. Bridging the Gap: Citizenship, Participation and Accountability. Brighton: Institute of Development Studies.

Govender, J. \& Reddy, P.S. 2011. The imperative of participation in South African local government. Africanus, 41(2):60-77.

Heller, P. 2001. Moving the state: the politics of democratic decentralization in Kerala, South Africa, and Porto Alegre. Politics \& Society, 29(1):131-163.

Heydenrych, P.W. 2008. Deepening democracy and enhancing multi-level governance: deficiencies of and prospects for local government ward committees in South Africa. Koers, 73(4):701-728.

Ingle, M. 2008. Exercising the mind with integrated development planning. Politeia, 26(1):5-17.

Madzivhandila, T.S. \& Asha, A.A. 2012. Integrated development planning process and service delivery challenges for South Africa's local municipalities. Journal of Public Administration, 47(1.1):369-378.

Mbambo, N. \& Tshishonga, M. 2008. Forging democracy from below: the challenges and imperatives of crafting community participation and engagement. Journal of Public Administration, 43(4.1):767-780.

McEwan, C. 2003. 'Bringing government to the people': women, local governance and community participation in South Africa. Geoforum, 34: 469-481.

Moseti, Y. 2010. "Public participation for sustainable development in local cities Public Participation for Sustainable Development in 
Local Cities", paper presented during the International Society of City and Regional Planners congress, 4th October 2010, Nairobi, Kenya.

Mubangizi, B.C. 2007. Service delivery for community development: reconciling efficiency and community participation with specific reference to a South African rural village. Journal of Public Administration, 42(1):4-17.

Nsingo, S.A. \& Kuye J.O. 2005. Democratic participation for service delivery in local government in Zimbabwe: humanising structural configurations and legal provisions. Journal of Public Administration, 40(2):744-760.

Nzimakwe, T.I. \& Reddy, P.S. 2008. Community participation in Ethekwini Municipality with particular reference to ward committees. Journal of Public Administration, 43(4.1):667-679.

Republic of South Africa (RSA), 1998. White Paper on Local Government, 1998. Pretoria: Government Printer.

Republic of South Africa (RSA), 2000. Local Government Municipal Systems Act 32 of 2000. Pretoria: Government Printer.

Piper, L. \& Deacon, R. 2008. Party politics, elite accountability and public participation: ward committee politics in the Msunduzi Municipality. Transformation, 66:61-81.

Pycroft, C. 2000. Democracy and delivery: the rationalization of local government in South Africa. International Review of Administrative Sciences, 66:143-159.

Tshabalala, E.L. \& Lombard, A. 2009. Community participation in the integrated development plan: a case study of Govan Mbeki Municipality. Journal of Public Administration, 44 (2):396 409.

Williams, J.J. 2006. Community participation: lesson from post-apartheid South Africa. Policy Studies, 27(3):198-217. 